coin that can be traced back to early sixteenth-century Bohemia; and the abiding fondness of one of the planet's most technically advanced nations for non-SI units is a source of some embarrassment or hilarity (depending on your point of view). The past is a loam of inertia through which the shoots of futurity struggle to emerge. As cyberpunk author William Gibson once said, the future is already here - it's just not very evenly distributed.

Wells had every reason to fight for the future. Fate saw him born into the smokes and stinks of Victorian Britain as the son of servants in 1866. Like all years, it was a potpourri of past and future: it was the year of the long-forgotten Austro-Prussian War between two ageing empires that have long since crumbled, but also the year that the Royal Aeronautical Society was founded, and that Alfred Nobel invented dynamite.

Wells nimbly avoided his fate of becoming a haberdasher and ended as one of the visionaries of his age, regularly published in these pages. Pulling himself upwards to the light became a personal as well as a professional preoccupation.

Living as we do in a much gentler age (for all that it occasionally seems otherwise), we are inclined to dissect Wells's achievement into discrete anticipations of such technological gewgaws as tanks and atomic bombs, without appreciating his drive and ambition to better not just himself, but the rest of humanity. We are likewise inclined to forget that his first full-length novel, The Time Machine, is not just a fantasy of the far future but an excoriating damnation of the class system, in which the classes evolve into two separate but interdependent species: the leisured, effete and mindless Eloi, preyed on by the ugly and industrious Morlocks. This is no hidden allegory: as a character says in The Soul Of A Bishop (1917), one of Wells's non-science-fictional novels, "we are the Morlocks, coming up!".
One could be flippant and say that the importance of Wells's work now lies in its intriguing mix of old and new - Wells was steampunk when steam was still punk, his futuristic machines tricked out in hand-tooled leather and knurled brass. But Wells earns his place, in the words of Brian Aldiss (in Trillion Year Spree), as the 'Shakespeare' of sci-fi because he takes ordinary people and tests their reactions to technology and its consequences - shaven monkeys from Woking
"The future is already here it's just not very evenly distributed." pitted against the intellects of Martians, vast and cool and unsympathetic.

Star Trek first aired in the centenary year of the US Civil Rights Act of 1866 — an appropriate date, seeing as the show's prime aim was to depict a harmoniously integrated future society rather than anticipate technological marvels such as the tricorder and the cloaking device. Arthur C. Clarke, another titan of sci-fi, dismissed (in The Songs of Distant Earth) one such technological trinket, the warp drive, as simply a McGuffin that allowed the crew to get from one locale to the next "in time for next week's exciting episode". Star Trek creator Gene Roddenberry, like Wells, drew his passion from a need to rise above the inequities of the present and forge a more equitable future.

Why are we celebrating Wells and Star Trek now, in this sci-fi special (which includes on page 259 our long-running Futures sci-fi series presented as a graphic novel for the first time)? It happens to be 150 years since Wells's birth, 70 years since his death and 50 years since Star Trek was first aired. All satisfying multiples of ten, but measured in units based on the revolution of a small planet round an unremarkable star in the suburbs of an ordinary galaxy. As Wells lamented, we are shackled to our past. It might be a while before we run such commemorations based on binary representations of elapsed numbers of Planck time units.
ANNOUNCEMENT

\section{Where are the data?}

A $s$ the research community embraces data sharing, academic journals can do their bit to help. Starting this month, all research papers accepted for publication in Nature and an initial 12 other Nature titles will be required to include information on whether and how others can access the underlying data.

These statements will report the availability of the 'minimal data set' necessary to interpret, replicate and build on the findings reported in the paper. Where applicable, they will include details about publicly archived data sets that have been analysed or generated during the study. Where restrictions on access are in place - for example, in the case of privacy limitations or third-party control - authors will be expected to make this clear.

The new policy (full details of which are available at go.nature. com/2bf4vqn) builds on our long-standing support for data availability as a condition of publication. It also extends our support for data citation, the practice of citing data sets in reference lists in a similar way to citing papers. Authors are encouraged to cite data sets that have digital object identifiers (DOIs) assigned to them.

The introduction of data-availability statements follows a trial at five Nature journals - Nature Cell Biology, Nature Communications, Nature Geoscience, Nature Neuroscience and Nature Physics - that began in March 2016. The pilot confirmed differences in the culture of data sharing and access between different disciplines, and that the lack of obvious, public, community repositories can pose a significant barrier to public data deposition. Nevertheless, even in disciplines that are not yet so able to embrace openness and sharing, there is increasing awareness and appreciation that data deposition can enhance the visibility and reuse of published research, and that data citation can increase the recognition of those who create and share data.

This new policy will be implemented across the diverse range of Nature journals by early 2017. We expect that its implementation will shed more light on the reasons for disciplinary differences in data sharing, identify challenges and help to promote the practice more widely.

It's not just journals. A broad drive across the research, funding and publishing communities is under way to make the availability of research data more transparent. Funders, for example, are also introducing data-availability statements. The seven UK research councils require their grant holders to include them. And the US National Institutes of Health is asking researchers to provide management plans for their research data.

We expect that offering consistent information on data availability in our papers will promote data reuse by future researchers. And where public data archiving is a mandatory requirement of journals, there is some evidence that including data-availability statements with persistent links to data in published articles is an effective approach to ensuring public data availability and policy compliance (T. H. Vines et al. FASEB J. 27, 1304-1308; 2013)

This new policy follows the launch, in July 2016, by our publisher Springer Nature of an ambitious project to introduce and standardize research data policies across all of its journals (see go.nature.com/2by616x). The project sets out a defined common framework for data policy - which Nature policies align with - that enables different journals to encourage data sharing in a way that reflects the circumstances of respective specialist communities. 